\section{The European identity}

\author{
Jerry A. Coyne
}

Journal of Evolutionary Biology. Managing editor S. C. Stearns. Birkhäuser. 6/yr. Swiss franc 288, elsewhere $\$ 192$; Society members SwFr. 70.

ONE of the striking aspects of evolutionary biology is its dominance by anglophones. Although the Society for the Study of Evolution is supposed to be an international organization, 92 per cent of its members are from English-speaking countries and its annual meetings are always held in North America. This has led some evolutionists, particularly in continental Europe, to feel that their contributions are discounted for linguistic reasons.

To provide a more international forum, the European Society of Evolutionary Biology and its official organ, Journal of Evolutionary Biology, were created in 1987. According to Stephen Stearns, its

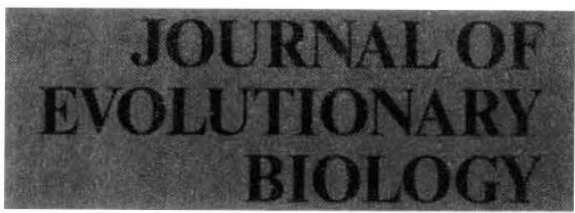

energetic editor, the journal also seeks to fill a void by "bringing together a set of specialities that have not previously shared a common arena for discussion" (Vol. 1, page 2), including systematics, molecular evolution, development, palaeontology, genetics and ecology. Each issue contains about five papers or notes, a few short book reviews and an occasional transcript of a talk from the annual meeting.

After two years, the journal has reached its first goal, but not its second. Thanks to a board of young editors from 13 countries, the quality of the papers is high, nearly equal to that of Evolution, by far the best journal in the field. There is also a good geographical mix of authors, more than 40 per cent of them from nonEnglish-speaking countries (Evolution has only a third as many). Although rapid publication is not terribly important in this field, the journal is faster than most, with nine to twelve months from submission to print. The illustrations are excellent, and the format (except for the garish red-andgreen cover) attractive.

But the gap that Journal of Evolutionary Biology seeks to occupy does not exist. For many years it has been comfortably filled - indeed, choked - by journals such as Evolution, The American Naturalist and The Biological Journal of the Linnean Society, all of which cover a NATURE · VOL 341 - 28 SEPTEMBER 1989 variety of evolutionary topics. In addition, the excellent Trends in Ecology and Evolution reviews developments in every area of population biology. Except for its high proportion of European authors, Journal of Evolutionary Biology is indistinguishable in content from Evolution, both of them having many papers on evolutionary quantitative genetics, sex and mating systems, the evolution of development, and life-history optimization. It is hard to see how, short of commissioning interdisciplinary review papers, the editors could create a new and broader perspective.

Unlike species, journals inhabiting the same niche may coexist indefinitely. It is possible that the increasing number of papers in the field or the more European character of the journal will keep it alive. It is also possible that the encouragement of contributors from more countries will elicit novel points of view (this has not happened yet). The editors should, however, fatten up the journal if it can be done without sacrificing quality. Members now pay the equivalent of $\$ 2.25$ per paper ( $\$ 4.75$ for libraries), nearly seven times the cost of each paper in Evolution. This disparity may decrease when more evolutionists realize that Journal of Evolutionary Biology is an attractive alternative to older publications.

Jerry A. Coyne is in the Department of Ecology and Evolution, University of Chicago, 1103 East 57th Street, Chicago, Illinois 60637, USA.

\section{Catastrophism}

\section{John Whittow}

Natural Hazards: An International Journal of Hazards Research and Prevention. Editors M. I. El-Sabh, G. Schneider and Y. Tsuchiya. Kluwer. 4/yr. Dfl. 272, North America $\$ 127.50$ (institutional); Dfl. 125, North America $\$ 59$ (personal).

IT Is hardly surprising that the beginning of the International Decade for Natural Disaster Reduction should be accompanied by the appearance of new journals. Although the topic has been extensively covered by books, both popular and academic, it has hitherto been poorly served by faster-moving specialist media.

The exception has been Disasters: The Journal of Disaster Studies and Management, which has run for more than a decade. As its name suggests, however, this publication is geared primarily to disaster relief and management research rather than to analysis of the physical processes involved (though such studies are by no means excluded). So one has been forced to search through a huge variety of engineering, atmospheric science, Earth science and occasionally social science journals to discover detailed information on natural hazards and their effects.

One should welcome, therefore, the appearance of two new journals in 1988Disaster Management: An International Journal of Contingency Planning for Large Scale Emergencies, which is published by Argus Press, Redhill, UK, and Natural Hazards, the subject of this review. The two differ somewhat, in that the first deals largely with human-induced incidents, while the second is mainly (but not exclusively) concerned with natural events.

Natural Hazards is the journal of the International Society for the Prevention and Mitigation of Hazards, a society spawned from the Rimouski International Symposium on Natural and Man-made Hazards, held in August 1986. The impressive list of 29 members on its editorial board is drawn from a variety of disciplines in no less than 17 countries. The journal has already been recognized as a forum for discussion and as having fostered a beneficial exchange of information between Earth scientists, engineers, planners and other policy makers. The editorial policy is to carry research articles on the physical processes, on the nature of their impact and on how such impacts may be ameliorated both by structural and non-structural means. Moreover, contributions on man-made and technological hazards are invited; it will be interesting to see the results, for there has been a noticeable increase in industrial hazard research during the past decade.

If the four issues of Vol. 1 are anything to go by, the response to the catholicity of the editorial approach has been reasonably successful. A wide selection of articles has been published, ranging in subject matter from earthquakes, volcaroes and debris flows to tsunamis, storm surges and coastal erosion. To illustrate the journal's even wider brief, there has also been a paper on simulation of oilslick movements.

The 400 pages of the first volume include 24 articles varying between eight and 22 pages in length. The remainder of the volume is taken up by a valuable "Chronicle" that previews forthcoming conferences, book reviews, a list of recent publications and a correspondence section. The quality of the contributions, though uneven, is acceptable and in general the journal design and production create a favourable impression.

The same cannot be said, however, for the quality of the cartographic material. There is a woeful inconsistency of style and worrying variation in the legibility of the diagrams; there is no place for freehand lettering and graphics in an international journal launched at the end of the 1980s.

John Whittow is in the Department of Geography, University of Reading, Whiteknights, Reading RG6 $2 A B$, UK. 